\title{
A Qualitative Study Exploring Healthy Eating and Physical Activity in Families with Young Children
}

\section{Rowena K. MERRITT* ${ }^{*}$, Michelle A. VOGEL ${ }^{1}$, Patrick LADBURY ${ }^{1}$}

1 Research Fellow, University of Kent, UK

*Auteur(e) correspondant | Corresponding author : r.k.merritt@kent.ac.uk

\section{Abstract:}

Keywords:

\section{Résumé :}

(traduction)

Mots-clés :
Overweight and obesity in childhood affects health long-term. Parent attitudes and behaviours play major roles in their child's weight despite no consensus on appropriate and effective family-focused interventions to successfully tackle childhood obesity. This research aims to explore caregiver perceptions, attitudes, and behaviours around children's diet, exercise, and weight in East Sussex. In-depth qualitative interviews with mothers, fathers, and grandparents of children aged 2-11 years were conducted. Caregivers wanted to influence their children's diet and exercise habits but were unable due to perceived and actual barriers. Barriers included cost, time, and a lack of control over food choices as children aged. Moreover, caregivers admitted to providing unhealthy sweets and snacks to please their children. While caregivers openly discussed their own weight concerns, they were less likely to discuss concerns about their children's or grandchildren's weight. When asked about the ideal amount of exercise, caregivers found it easy to describe a regime for adults but did not know the ideal amount of exercise for children. Many caregivers found it difficult to quantify exercise when it came to their children because children naturally played in ways that could be considered exercise. Family-based interventions should begin in early childhood and promote walking and dog-walking as forms of exercise, parental education on childhood exercise guidelines, and preparing and eating healthy home-cooked meals in the home.

Childhood obesity, pediatric nutrition, qualitative research

Le surpoids et l'obésité infantile affectent la santé à long terme. Les attitudes et les comportements parentaux ont des répercussions importantes sur le poids des enfants, mais il n'existe aucun consensus sur les interventions familiales appropriées et efficaces servant à combattre l'obésité infantile. Ce travail de recherche vise à explorer les perceptions, les attitudes et les comportements des fournisseurs de soins à East Sussex liés à la diète, à l'exercice et au poids des enfants. Des entrevues qualitatives approfondies ont été menées auprès de mères, de pères et de grands-parents d'enfants âgés de 2 à 11 ans. Les fournisseurs de soins souhaitent influencer les habitudes alimentaires et en matière d'exercice des enfants, mais ne sont pas en mesure de le faire en raison d'obstacles réels et perçus, notamment le coût, le temps et le manque de contrôle sur le choix des aliments à mesure que les enfants vieillissent. De plus, les fournisseurs de soins ont avoué offrir aux enfants des sucreries et des collations pour leur faire plaisir. Les fournisseurs de soins ont ouvertement exprimé leurs préoccupations concernant leur propre poids, mais ont moins ouvertement discuté de leurs préoccupations liées au poids des enfants. En ce qui concerne la quantité idéale d'exercice, les fournisseurs de soins pouvaient facilement décrire un programme d'exercice pour adultes, mais ne connaissaient pas la quantité idéale d'exercice pour les enfants. Plusieurs fournisseurs de soins avaient de la difficulté à quantifier l'exercice chez les enfants, car ces derniers jouent naturellement de manière active. Les interventions familiales devraient commencer dès la jeune enfance et promouvoir la marche et la promenade de chiens comme forme d'exercice, la formation des parents sur les lignes directrices en matière d'exercice chez les enfants, ainsi que la préparation et la consommation de repas sains préparés à la maison.

Obésité infantile, alimentation pédiatrique, recherche qualitative 


\section{Introduction}

It is estimated that 42 million children worldwide under the age of five were overweight or obese in 2013 (World Health Organization, 2015). Overweight and obesity in children and adolescents is defined using body mass index (BMI, weight $[\mathrm{kg}] / \mathrm{height}[\mathrm{m}]^{2}$ ) and is associated with longterm negative health consequences including hypertension and type 2 diabetes (Biro \& Wien, 2010; Deckelbaum \& Williams, 2001). Moreover, childhood obesity is a strong predictor of adult obesity and premature death (Franks et al., 2010; Reilly \& Kelly, 2011; Whitaker, Wright, Pepe, Seidel, \& Dietz, 1997). Behavioural factors such as diet and physical activity play integral roles in weight management in childhood (Roblin, 2007; Steinbeck, 2001). Caregivers influence the diet and exercise habits of their children; they serve as role models and often dictate their child's schedule and lifestyle (Moore, Harris, \& Bradlyn, 2012).

Cross-sectional studies have demonstrated important relationships between parenting behaviours and the dietary intake and physical activity levels of their children. First, children eat more when dining in restaurants compared to eating at home (Zoumas-Morse et al., 2001). Second, children whose families eat together have better diet qualities and watch less television (Wiecha et al., 2001). Third, children who receive social support from parents, peers, siblings, or teachers have higher levels of physical activity (Sallis, Prochaska, \& Taylor, 2000). Moreover, parents of children with overweight or obesity largely fail to identify their child as having overweight or obesity (Etelson et al., 2003) despite worrying their child will develop obesity in the future (Carnell et al., 2005). Despite the known associations between parenting behaviours and dietary intake and physical activity levels in children, caregivers' attitudes and behaviours towards their child's weight are not well understood. Moreover, there is no consensus on an appropriate and effective family-focused dietary and physical activity intervention for decreasing childhood overweight and obesity. Therefore, this research aims to explore perceptions, attitudes, and behaviours surrounding diet, exercise, and body weight in families with children aged 2-11 years.

\section{Methodology}

\section{Caregivers}

In this qualitative formative research study, caregivers were selected using purposive sampling and were recruited through local children's centres as well as through a market research company, Plus4, from six wards with the highest combined prevalence of overweight and obesity in East Sussex, UK. Caregivers were eligible if they had at least one child or grandchild aged between 2-11 years. The research team recruited from areas where a good percentage of the population had overweight/obesity but did not ask caregivers to report BMI to avoid stigmatization. After obtaining consent from mothers, fathers, and grandparents, researchers interviewed caregivers individually. Interviews were semi-structured using a topic guide (Appendix I) and took place between June and August 2015. Caregivers were offered the opportunity to be interviewed in their own home, over the telephone, or in a community venue of their choice. They were compensated $£ 25$ for their time.

\section{Data Analysis}

Interviews were audio-recorded and transcribed verbatim using NVivo (QSR International Pty Ltd, 2012). Interview transcripts were coded into main themes and subthemes by two independent researchers. The results were categorized into four main themes: 1) current family diet and exercise behaviours; 2) perceptions of weight; 3) barriers to healthy eating; and 4) barriers to exercising. These themes were drawn from the data once it was collected and analyzed using Grounded Theory (Glaser \& Strauss, 1967).

\section{Results}

\section{Caregivers}

Thirty-six in-depth qualitative interviews were conducted with 30 mothers, three fathers, and three grandparents of low-to-middle socioeconomic status. Caregivers were, on average, 36-years-old (range: 23 to 55 years). Six caregivers had only one child or grandchild, while 30 caregivers (83\%) had more than one child or grandchild. Of those who had more than one child, 18 caregivers $(50 \%)$ had two children or grandchildren. Twenty-eight of the 36 caregivers (78\%) were employed (full or part-time). The median length of the interview was 44 minutes. Ten interviews were conducted face-to-face and the rest were conducted over the phone.

\section{Dietary Practices}

While caregivers said both they and their children preferred comfort foods, they often fed their children different meals from what they ate themselves. Caregivers cited comfort foods (e.g. curry, spaghetti Bolognese, jacket potatoes, and roast dinners) as being their own favourite foods and, similarly, their child's favourite foods. Caregivers said they ate healthy breakfasts (e.g. yogurt with fruit or muesli) or no breakfast at all. However, they often fed their children different foods including unhealthy, sugary cereals for breakfast. Even though a few caregivers skipped breakfast, all provided breakfast for their children.

"I normally have either grapefruit or strawberries and fat free yogurt or I mix myself up a mixed berry shake or a banana and strawberry shake. My daughter on the other hand I normally give her coco pops or Weetabix." (Mother of one, 28 years old)

Children ate different foods at lunchtime depending on whether they were at school or home. If they went to school, parents discussed giving them packed lunches with sandwiches, crisps, and fruit, or letting them eat the lunch provided by the school cafeteria. At home, children ate hot 
meals such as pastas or baked beans. Dinner was the largest and most varied meal amongst all caregivers. Neither parents nor children skipped dinner. A few of the caregivers expressed frustration that their children did not like to eat fruit and vegetables, or that their children seemed to go through phases of liking or not liking certain foods. To mitigate the nutritional imbalance caused by fussiness, one parent added vegetables to meals by disguising them or blending them into soup.

"Yeah, they're a bit funny with the veg[etables].... But I do disguise it, like I say, if I'm making food.... I just sort of blend it up and get veg[etables] in their food that way." (Father of three, 45 years old)

"Mealtimes are a battle. Food is a big issue in my house for me as I don't want my children to grow up and turn out the way he [overweight husband] has.... And for me meal times are very important and I sit down with them. But I have a four-year-old who would live on spaghetti Bolognese if he could. He's just got picky from the age of threeyears-old; he is just so fussy. I have to try... where I feel he misses out at dinner...I have to try and make up with other things, like fruit. He gets a cooked dinner at school but I don't know what he is actually eating as he is so picky." (Mother of one, 36 years old)

Overall, it was clear that caregivers and children did not share the same diets or food preferences. Caregivers felt their children should not and would not eat the same way they did. For instance, caregivers who followed a vegetarian diet did not believe this diet was suitable for their children. Moreover, caregivers reported higher avoidance and refusal to eat certain foods (e.g. spicy foods) among their children. Finally, caregivers regarded certain foods as specifically formulated for children (i.e. breaded chicken and sugary cereals).

"They like what I call 'beige foods', burgers and chips, pizza, that type of thing." (Grandparent, 55 years old)

"My wife cooks her slimming club meals, my kids always say is that your fat club food? They don't eat that and I wouldn't want them to, I don't really want to eat it either! I wouldn't want them to think about diet and weight at their age." (Father of one, 27 years old)

\section{Physical Activity Behaviours}

Most caregivers mentioned walking, both alone and with their children, multiple times a week. They walked in parks, on nature trails, around their local neighbourhoods, and to and from shops. Walks were said to last anywhere from 15 minutes to four hours, but the average was roughly one hour. Most caregivers owned a pet and mentioned walking the dog as a popular family pursuit. For some families, walking was their main form of transportation. Caregivers discussed other sports and activities that their children engaged in as well; however, none were as popular as walking. For primary school-aged children, the next most popular form of physical exercise was playing on local sport teams. Other physical activities mentioned for their children in- cluded swimming, cycling, dancing, roller blading, martial arts, and jumping on the trampoline, but these were not as popular as walking.

"Just lots of walking. Like we do like to go out obviously where we are like right by the coast and we've got the downs and stuff like that so a fair amount of walking." (Mother of three, 36 years old)

"But we quite like to go on bike rides... She has a swimming lesson once a week.” (Mother of one, 28 years old)

"I do pay for swimming lessons for [grandson's name] as I am not a good swimmer. In fact, I did not learn until I was a teenager and still I am a bit scared to go under [the water]. So I didn't want my kids or grandkids to be the same as me. I see that as important." (Grandparent, 55 years old)

\section{Caregivers' Perceptions of Self and Child's Body Weight}

Many caregivers regarded their own weight as slightly higher than ideal, but were not concerned health-wise. When asked what a child of healthy weight looked like, many caregivers emphasized being neither too thin nor fat, but having a little tummy or 'puppy fat' if prepubescent.

"A healthy child should have, like you say, glowing cheeks but a little bit of weight on them. I don't think a skinny baby is... it's not right, that's not right for a child to be skinny. Not at all." (Mother of three, 36 years old)

Most caregivers who expressed concern about their child's weight were concerned their child was too thin.

"I have been a bit concerned but intermittently throughout her whole life that she's so slim and in her younger days when she was like probably between four and ten months, I'd feel like I was [visiting] the health visitor drop-in clinic

like every other week getting her weighed like, 'Are you sure this is normal?"' (Mother of one, 25 years old)

One parent alluded to being worried that her daughter was overweight, but no caregivers expressed concern outright.

"It's funny because at her dancing lesson they all wear leotards and they all line up next to each other and you can see they're all such different shapes and I have worried 'God is she fat?' She's not at all and she really isn't but kids are built differently." (Mother of one, 28 years old)

Overall, caregivers openly discussed their own weight concerns but were less likely to report concerns about their children's weight. They feared this may cause their children to worry and become obsessed with their weight.

"To be honest, I'm very aware of, I do not want to be too careful with healthy eating as my older daughter had ano- 
rexia and bulimia. So I am conscious not to say too much about eating healthily...yeah, I focus on balance as opposed to health." (Mother of two, 42 years old)

"I know I'm not alone, I know there are lots of mothers like me. If I say you are not going to leave the table till you eat this he will eat it then throw up all over the floor so it's about giving them a balance, a mix of foods they like and new foods to try." (Mother of one, 26 years old)

\section{Barriers to Healthy Eating}

Caregivers said the major barriers to making sure their children were eating healthily were cost, time, and a lack of control over food choices as their children got older and more independent. Knowledge was not identified as a barrier to eating healthily as all caregivers described an ideal, healthy diet as one with fruits and vegetables, lean proteins, and water as the drink of choice. Diets high in carbohydrates, fats, and sugars were viewed as unhealthy. Almost all caregivers considered maintaining a healthy diet as more expensive than buying less nutritious foods. As most caregivers worked full-time, insufficient time and convenience were major barriers to feeding healthy meals. Despite knowing home-cooked meals were healthier, caregivers felt they did not have the time to cook on several days and, therefore, chose quicker and less nutritious options to feed their children.

"There are so many things against mothers these days; time, cost. I know how to cook from scratch, I'm lucky as my mother taught me, but it is tough for working mothers these days." (Mother of two, 31 years old)

As the children aged, caregivers felt they had decreasing control over their children's eating and one caregiver reported frustration over his inability to regulate his son's unhealthy dietary choices.

"If they've got $£ 1$ in their pocket I can't stop them [from] buying a packet of crisps and a chocolate bar when they want it if they've got the money. I just try and say to them that there's better things to [eat?]..." (Father of three, 45 years old)

Other barriers to feeding their children healthy food including marketing of unhealthy foods to children (i.e. colourful packaging with familiar cartoons) and a lack of healthy food delivery options.

"I know people can go out and get lettuce and salad and god knows what and make their salads and get their healthy food but I think that...I don't think that there's such a thing as someone getting a delivery of a salad or something as healthy." (Father of four, 33 years old)

Barriers to Physical Activity

When asked about the ideal amount of exercise, caregivers found it easy to describe a regime for adults but did not know the ideal amount of exercise for children. Many caregivers said adults should exercise about thirty minutes to an hour per day, five to seven days a week. A few caregivers said they simply did not know how much a child should exercise, while some estimated anywhere from ten minutes to two hours every day. As most children were constantly on the move, some caregivers found it difficult to quantify physical activity in children.

"So they're constantly on the go. You know, like we went to Peppa Pig World yesterday and I don't think he actually walked anywhere; like he was skipping and jumping and everything so you don't know, is that exercise?"

"My daughter, being a girl, I'm not sure if she would be different than my son." (Father of two, 28 years old)

Caregivers did not view physical activity as a priority and, therefore, did not motivate their children to exercise. Some caregivers reported insufficient time and energy to exercise with their children and caregivers of toddlers felt especially challenged given their child could not run, bike, or swim at their age.

"There's no kind of family activities. I mean not with him at this age. I know that they do quite a few cycling things around here but he's not at that age where he can cycle. ... you know, there's been nothing that the three of us would go oh what should we do today? Let's go and do that." (Mother of one, 30 years old)

Even though some caregivers mentioned walking outdoors with their pets as a common form of exercise, a few caregivers said they thought their physical environment was a barrier to exercising for both themselves and their children. They discussed environmental barriers including being stuck in their apartment with the lack of a car to go to the gym or the park. Similarly, caregivers reported recent technological advances have led to increased convenience and inactivity.

"Motivation is not there because it's all been handed to us on a plate - I believe that anyway, you know, apart from activities like let's say for instance snowboarding where you have to get off your butt and do something. It's the same with working in my opinion: people are using computers, everyone can get their information on YouTube, everyone can watch films." (Father of four, 33 years old)

\section{Discussion}

Caregivers wanted to influence their children's diet and exercise habits but were unable due to perceived and actual barriers. Past family-based interventions have at times been successful in changing behaviours but not in reducing children's BMI and overweight or obesity risk (Ebbeling et al., 2002). In a study that compared an experimental, parentcentered intervention to a control, child-centered intervention, the parent-centered approach was significantly more 
successful in reducing the mean weight of children with obesity (Golan, 2006). This study supports the idea that family-centered interventions should focus on parents as the change agents for the entire family. Family exercise programmes should include less intensive and more sustainable physical activities like walking, which was a popular activity among our caregivers.

One common recommendation in the literature is that interventions should focus on providing parents with the tools to translate knowledge into behaviours when it comes to reducing childhood overweight and obesity (Zehle et al., 2007). This is important given that the caregivers in our study were largely unaware of national physical activity guidelines for children and were unable to define exercise in their children. However, increasing knowledge appears less necessary for dietary interventions as caregivers understood that fruits, vegetables, and water represented components of a healthy diet. In this case, to improve healthy eating practices, programmes should focus on eliminating barriers instead of increasing knowledge.

One issue identified by our research was the feeling that as their children aged, caregivers had less control over their children's eating choices. Starting healthy feeding habits in early life could mitigate these issues as children mature (Gardner et al., 2009; Moss \& Yeaton, 2014). These habits can be promoted during antenatal visits and when community health workers visit homes. Health workers visit homes before the baby is born then take over from the midwife when the baby is around 10-14 days old. They stay engaged with the child until around five years old, once the child is in school. Our research and the work by others suggest that caregivers are uncomfortable discussing overweight or obesity with their children (Pocock, Trivedi, Wills, Bunn, \& Magnusson, 2010). Caregivers fear this may instill self-consciousness, weight stigmatization, and judgement (Pocock et al., 2010; Toftemo, Glavin, \& Lagerløv, 2013; Wansink, Latimer, \& Pope, 2017). Ultimately, caregivers do not want their children to be concerned about their weight the way parents are with their own weight (Pocock et al., 2010). Family-centered interventions should emphasize the importance of living a healthy lifestyle by consuming a healthy diet and engaging in physical activity as opposed to implementing rules and restrictions in behaviours.

\section{Limitations}

This research is not presented without limitation. Limitations include self-reporting of all data, including dietary intakes and physical activity, which may have been influenced by social desirability bias. Moreover, we did not measure BMI in caregivers and, therefore, could not determine overweight or obesity. Although we included fathers and grandparents, the majority of our sample was mothers and, thus, we could not stratify our sample to detect differences amongst caregivers. Although dietary intake and physical activity are known to differ amongst males and females and in different age groups, we did not assess caregivers' perceptions for these groups independently.

\section{Conclusion}

There has yet to be consensus on the most effective familybased intervention to decrease childhood overweight and obesity. Family-based intervention programmes should start in early life and should feature walking and dogwalking as forms of exercise, parental education on childhood exercise guidelines, and preparing and eating healthy meals in the home. Our findings may inform the future commissioning of programmes that promote positive and sustainable changes in healthy eating and physical activity behaviours.

\section{Acknowledgements}

We would like to thank all the fathers, mothers, and grandparents who took part in the study. This research was funded by East Sussex County Council Public Health.

\section{References}

Biro, F. M., \& Wien, M. (2010). Childhood obesity and adult morbidities. The American Journal of Clinical Nutrition, 91(5), 1499S-1505S. http:// doi.org/10.3945/ajen.2010.28701B

Carnell, S., Edwards, C., Croker, H., Boniface, D., \& Wardle, J. (2005). Parental perceptions of overweight in 3-5 y olds. International Journal of Obesity, 29(4), 353-355. http://doi.org/10.1038/sj.ijo.o802889

Deckelbaum, R. J., \& Williams, C. L. (2001). Childhood obesity: the health issue. Obesity Research, 9 (Suppl 4), 239S-243S. http://doi.org/10.1038/oby.2001.125

Dietz, W. H. (1998). Health consequences of obesity in youth: childhood predictors of adult disease. Pediatrics, 101(3 Pt 2), 518-525. http://doi.org/10.1007/ s12098-011-0489-7

Ebbeling, C. B., Pawlak, D. B., \& Ludwig, D. S. (2002). Childhood obesity: public-health crisis, common sense cure. Lancet, 360(9331), 473-82. http:// doi.org/10.1016/So140-6736(02)09678-2

Etelson, D., Brand, D. a, Patrick, P. a, \& Shirali, A. (2003). Childhood obesity: do parents recognize this health risk? Obesity Research, 11(11), 1362-1368. http:// doi.org/10.1038/oby.2003.184

Franks, P. W., Hanson, R. L., Knowler, W. C., Sievers, M. L., Bennett, P. H., \& Looker, H. C. (2010). Childhood Obesity, Other Cardiovascular Risk Factors, and Premature Death. New England Journal of Medicine, 362(6), 485-493. http://doi.org/10.1056/

NEJMoao904130 
Gardner, D. S. L., Hosking, J., Metcalf, B. S., Jeffery, A. N., Voss, L. D., \& Wilkin, T. J. (2009). Contribution of early weight gain to childhood overweight and metabolic health: a longitudinal study (EarlyBird 36). Pediatrics, 123(1), e67-e73. http://doi.org/10.1542/ peds.2008-1292

Glaser, B. G., \& Strauss, A. L. (1967). The discovery of grounded theory. International Journal of Qualitative Methods, 5, 1-10. http://doi.org/10.2307/588533

Golan, M. (2006). Parents as agents of change in childhood obesity--from research to practice. International Journal of Pediatric Obesity: An Official Journal of the International Association for the Study of Obesity, 1(December 2005), 66-76. http:// doi.org/10.1080/17477160600644272

Gruber, K. J., \& Haldeman, L. A. (2009). Using the family to combat childhood and adult obesity. Prev Chronic Dis, 6(3), A106. http://www.cdc.gov/pcd/ issues/2009/jul/o8_0191.htm

Moore, L. C., Harris, C. V., \& Bradlyn, A. S. (2012). Exploring the relationship between parental concern and the management of childhood obesity. Maternal and Child Health Journal, 16(4), 902-908. http:// doi.org/10.1007/s10995-011-0813-X

Moss, B., \& Yeaton, W. (2014). Early Childhood Healthy and Obese Weight Status: Potentially Protective Benefits of Breastfeeding and Delaying Solid Foods. Maternal and Child Health Journal, 18(5), 1224-1232. http://doi.org/10.1007/s10995-013-1357-Z

Pocock, M., Trivedi, D., Wills, W., Bunn, F., \& Magnusson, J. (2010). Parental perceptions regarding healthy behaviours for preventing overweight and obesity in young children: A systematic review of qualitative studies. Obesity Reviews, 11(5), 338-353. http:// doi.org/10.1111/j.1467-789X.2009.00648.x

QSR International Pty Ltd. (2012). Nvivo. Retrieved from http://www.qsrinternational.com/

Reilly, J. J., \& Kelly, J. (2011). Long-term impact of overweight and obesity in childhood and adolescence on morbidity and premature mortality in adulthood: systematic review. International Journal of Obesity (2005), 35(7), 891-898. http://doi.org/10.1038/ ijo.2010.222

Roblin, L. (2007). Childhood obesity: food, nutrient, and eating-habit trends and influences. Applied Physiology, Nutrition, and Metabolism, 32(4), 635-645. http://doi.org/10.1139/Ho7-046

Sallis, J. F., Prochaska, J. J., \& Taylor, W. C. (2000). A review of correlates of physical activity of children and adolescents. Medicine and Science in Sports and Exercise, 32(5), 963-975. Retrieved from http:// www.scopus.com/inward/record.url?eid=2-s2.0o034056937\&partnerID=tZOtx3y1

Steinbeck, K. S. (2001). The importance of physical activity in the prevention of overweight and obesity in childhood: a review and an opinion. Obesity Reviews: An Official Journal of the International Association for the Study of Obesity, 2(2), 117-130. http:// doi.org/10.1046/j.1467-789x.2001.00033.x

Toftemo, I., Glavin, K., \& Lagerløv, P. (2013). Parents' views and experiences when their preschool child is identified as overweight: A qualitative study in primary care. Family Practice, 3o(6), 719-723. http:// doi.org/10.1093/fampra/cmto56

Wansink, B., Latimer, L. A., \& Pope, L. (2017). “Don't eat so much:" how parent comments relate to female weight satisfaction. Eating and Weight Disorders, 22(3), 475 -481. http://doi.org/10.1007/s40519-016-0292-6

Whitaker, R. C., Wright, J. A., Pepe, M. S., Seidel, K. D., \& Dietz, W. H. (1997). Predicting Obesity in Young Adulthood from Childhood and Parental Obesity. New England Journal of Medicine, 337(13), 869-873. http://doi.org/10.1056/NEJM199709253371301

Wiecha, J. L., Sobol, A. M., Peterson, K. E., \& Gortmaker, S. L. (2001). Household television access: Associations with screen time, reading, and homework among youth. Ambulatory Pediatrics, 1(5), 244-251. https:// doi.org/10.1367/1539-4409(2001) 001<0244:HTAAWS>2.0.CO;2

World Health Organization (WHO). (2015). Factsheet: Obesity and overweight. Retrieved December 2, 2015, from http://www.who.int/mediacentre/factsheets/ fs311/en/

Zehle, K., Wen, L. M., Orr, N., \& Rissel, C. (2007). “It's not an issue at the moment": a qualitative study of mothers about childhood obesity. MCN. The American Journal of Maternal Child Nursing, 32(1), 36-41. http://doi.org/10.1097/00005721-200701000-00008

Zoumas-Morse, C., Rock, C. L., Sobo, E. J., \& Neuhouser, M. L. (2001). Children's patterns of macronutrient intake and associations with restaurant and home eating. Journal of the American Dietetic Association, 101 (8), 923-925. http://doi.org/10.1016/Sooo2-8223 (01)00228-0 